\title{
DESENVOLVIMENTO ECONÔMICO E MUDANÇA SOCIAL: a Vale e a mineração na Amazônia Oriental
}

\author{
Rodrigo Salles Pereira dos Santos*
}

\begin{abstract}
O artigo propõe um aporte teórico socioantropológico acerca do fenômeno do desenvolvimento econômico e suas expressões contemporâneas, integrando-os à tradição da mudança social. Recupera o debate da sociologia do desenvolvimento brasileira e dialoga com o subcampo da antropologia do desenvolvimento, enfocando a Amazônia Oriental como um recorte empírico desafiador de concepções uniescalares e centradas em agentes privilegiados. O implante da extração mineral de ferro nos anos 1980 e sua ampliação exponencial a partir dos anos 2000 via 'grandes projetos' - o PFC e o PFC S11D, demonstraram capacidade indutora de transformação estrutural, mas evidenciaram, paralelamente, sua natureza social, complexa e multiescalar. Desse modo, o artigo enfatiza as relações entre agência, interação e estruturas sociais, localizando a relevância progressiva de padrões organizacionais de contestação em redes multiagentes com escopo transnacional. A investigação se apoia em pesquisa bibliográfica e revisão de literatura, assim como, secundariamente, em trabalho de campo e observação direta.
\end{abstract}

Palavras-chave: Desenvolvimento Econômico. Mudança Social. Grandes Projetos. Mineração. Vale.

\section{INTRODUÇÃO}

Este artigo busca contribuir com a retomada de um campo de debate comum às ciências sociais sobre o desenvolvimento econômico. Partindo de abordagens teórico-metodológicas da sociologia e da antropologia e apoiadas na ampla tradição da mudança social, discute o caso empírico da extração mineral de ferro na Amazônia Oriental, aportando elementos para a emergência de uma perspectiva interdisciplinar e multiescalar acerca dos processos de desenvolvimento contemporâneos.

Em primeiro lugar, levando em consideração que o fenômeno reassumiu escopo relevante na reprodução socioeconômica e cultural de contingentes populacionais expressivos no Brasil a partir dos anos 2000, defende-se que seus significados e usos práticos (e, por isso, disputáveis), atribuídos por agentes diversificados em suas relações cotidianas, conferem centralidade ao debate do desenvolvimento. Como

* Universidade Federal do Rio de Janeiro (UFRJ). Departamento de Sociologia e do Programa de Pós-Graduação em Sociologia e Antropologia (PPGSA)

Largo de São Francisco, 1, sala 420. Cep: 20051-070. Rio de Janeiro - Rio de Janeiro - Brasil. santosrodrigosp@gmail.com categoria nativa e objetivo capaz de conferir legitimidade e justificação a agentes políticos e econômicos, o desenvolvimento reingressou ativamente no campo das ciências sociais, não sem trazer consigo uma 'bagagem' normativa equivalente a sua relevância heurística.

$\mathrm{O}$ artigo articula pretensões de um ensaio acerca do problema do desenvolvimento como objeto socioantropológico, buscando integrar debates tradicionalmente dissociados a partir de revisão não exaustiva da literatura a uma perspectiva consistente e original sobre o tema; assim como se apoia em pesquisa bibliográfica e dados secundários de um lado, e, de outro, em trabalho de campo e observação realizados na Amazônia Oriental em dois períodos (2008 e 2009), além de visitas de campo pontuais desde então.

Além deste breve argumento introdutório e de sua seção conclusiva, o texto está dividido em três partes. A seção subsequente busca singularizar as contribuições da sociologia do desenvolvimento no Brasil (Costa Pinto, 1972), que atinge seu ápice nos anos 1960 e chega ao ocaso nos anos 1980, acompanhando a transformação progressiva dos papéis de- 
senvolvimentistas do Estado nacional. Por sua vez, a seção que a sucede avalia um recorte expressivo e empiricamente orientado do debate da antropologia do desenvolvimento - a socioantropologia de De Sardan (1995, 2005) -, que vem adquirindo maior influência nesse subcampo a partir de um enfoque centrado no conflito e nas relações de poder locais.

Tais contribuições são contrapostas, em seguida, a uma análise descritiva de projetos extrativos minerais de larga escala implantados pela Vale S.A. (Vale) na Amazônia Oriental o Projeto Ferro Carajás (PFC) e o Projeto Ferro Carajás S11D (PFC S11D), evidenciando a dimensão indutora de mudança social de eventos econômicos de grande magnitude, assim como as diferentes escalas a partir das quais os agentes econômicos operam efetivamente - o que coloca questões relevantes às formas habituais de investigação sobre processos relacionados ao desenvolvimento nas ciências sociais.

Essa discussão é complementada pelo delineamento de uma forma específica de investigação socioantropológica do desenvolvimento. Centrada em uma perspectiva multiagência, ela confere destaque aos agentes econômicos e suas estratégias, mas preserva caráter relacional, integrando as formas de agência não econômica e os processos sociopolíticos multiescalares que conduzem à própria defini: ção do desenvolvimento. A seção final articula os argumentos defendidos ao longo do trabalho a uma crítica antinormativa, colocando ב̂ alguns desafios e oportunidades à adoção de uma agenda de pesquisa relacionada ao desenvolvimento como mudança social.

$\stackrel{2}{n}$

ปึ A TRADIÇÃO ‘ESQUECIDA' DA SO$\because$ CIOLOGIA DO DESENVOLVIMENTO

No campo acadêmico brasileiro, emergia, desde fins da década de $1950,{ }^{1}$ um deba-

${ }^{1} \mathrm{O}$ período sintetizava determinações econômicas e políticas, internas e externas, que atualizavam a 'promessa' desenvolvimentista. Mais do que nunca, a industrialização, carreada pelo Estado, mas articulada ao influxo de capitais te acerca do desenvolvimento econômico no campo da sociologia ${ }^{2}$ (Costa Pinto,1960), assumindo características indutiva e histórica (Machado Neto, 1963, p. 8). É notável que essa produção esteja compreendida nos anos 1960, iniciando seu declínio na década posterior e, virtualmente, desaparecendo dos anos 1980 em diante. ${ }^{3}$

Às publicações que fazem uso do termo 'Sociologia do Desenvolvimento' em seus títulos, tais como Machado Neto (1963), Beltrão (1965), Pereira (1970) e Pinto Ferreira (1978), se agrega um amplo e considerável tratamento sociológico da temática (Brandão Lopes, 1964; Pereira, 1969; Brandão Lopes, 1976), tendo nas obras de Costa Pinto (1972; 1978), Costa Pinto e Bazzanella (1967; 1969), Cardoso e Faletto (1967) e Cardoso (1969) sua mais completa representação.

Recuperar algumas de suas contribuições pode auxiliar na compreensão de processos de desenvolvimento contemporâneos, assim como estimular um diálogo interdisciplinar necessário com a antropologia do desenvolvimento. Alguns desses aportes tendem, inclusive, a produzir interpretações menos normativas do fenômeno.

Seu principal elemento aglutinador diz respeito à definição do próprio objeto, cuja compreensão apropriada remete à oposição entre tradicional e moderno, prevalente na tradição sociológica e 'manifesta' no contexto latino-americano do período. Dessa forma, Costa Pinto (1972, p. 96) define o desenvolvimento

externos, de um lado, e a migração e a urbanização, de outro, se tornaram as formas específicas da mudança social no Brasil.

${ }^{2} \mathrm{O}$ 'Seminário Internacional sobre Resistências à Mudanç: fatores que dificultam ou impedem o desenvolvimento econômico', que reuniu estudiosos do tema como C. Wright Mills e Gino Germani, dentre outros, no Museu Nacional, Rio de Janeiro em 1959, pode ser considerado o ponto de partida nesse itinerário.

${ }^{3}$ Sua recuperação desde os anos 2000 se relaciona a processos de reorientação temática nas subdisciplinas do pensamento social e da sociologia do trabalho, sendo operada, por exemplo, através do reingresso do termo 'desenvolvimento’ nos títulos de seminários temáticos da ANPOCS desde 2004 e do adensamento de artigos (Ivo, 2012), livros (Ramalho; Fortes, 2012) e dossiês temáticos (Ramalho; Oliveira, 2013; Leme; Brasil Jr., 2015). 
econômico como "uma configuração específica, historicamente definida, do processo geral de mudança social”, enquanto, para Brandão Lopes (1976, p. 13xiii), o "desenvolvimento é entendido como envolvendo, em essência, mudança estrutural da sociedade e da economia”.

A concepção do desenvolvimento como mudança social estrutural assumiu, assim, enorme relevância na abordagem, conferindo centralidade às relações sociais em sua conformação e apresentando uma perspectiva nitidamente dinâmica. Nesse sentido, o fenômeno do desenvolvimento é integrado à tradição sociológica da mudança social, vista como a acumulação de variações em extensão e intensidade significativas, indutora de transformações sistêmicas em diferentes escalas de estruturas sociais (Sztompka, 2005, p. 30), específicas temporalmente e localizadas espacialmente.

É discernível a preocupação de alguns de seus principais representantes em 'disputar' os sentidos do fenômeno no campo intelectual. Contrapondo-se a definições economicistas, a abordagem questionava fortemente a identificação - e, posteriormente, a subordinação - do desenvolvimento ao crescimento econômico ${ }^{4}$ (Costa Pinto, 1978, p. 29).

Nesse sentido, o esforço de construção do desenvolvimento como objeto sociológico, integrado à tradição da mudança social, derivou, desde o início, em um enfoque analítico centrado na industrialização e na urbanização (Brandão Lopes, 1976, p. 13). Desse modo, os fenômenos da industrialização - visto como a conversão de socioeconomias rurais em industriais - e da urbanização - ou "constituição gradativa ou desenvolvimento localizado do urbanismo e [...] assimilação [...] de contingentes populacionais rurais imigrados" (Pereira, 1970, p. 104) - constituíam os parâmetros de uma agenda de pesquisa comum.

Nesse contexto, sua unidade de análi-

${ }^{4}$ A exclusividade do 'econômico' teria sido deslocada pela subsidiariedade do 'social', de modo que o desenvolvimento tende a ser definido como "uma espécie de brinde Bonux que se pode encontrar por acaso em um pacote de crescimento econômico", noção contra a qual se dirige a crítica de Baré (2004, p. 103). se remetia ao conjunto variado de fenômenos constituintes do processo de desenvolvimento, que ora abrangia formas específicas ao contexto 'dependente' latino-americano, da crítica econômica à "industrialização retardatária" (Cardoso De Mello, 1982) e à sociológica da “urbanização sociopática” (Pereira, 1969, p. 61); ora assumia a forma de análises sintéticas de suas dimensões, incorporando a "modernização” (Germani, 1974; Brandão Lopes, 1976), ou o 'reverso da moeda', o subdesenvolvimento (Pereira, 1973).

A assimilação do desenvolvimento como fato passível de investigação empírica, visto predominantemente em sua dimensão fenomênica, constitui, portanto, uma das características mais típicas da abordagem, definindo um enfoque que postula a identidade entre o fenômeno e vida social concreta (Costa Pinto, 1972, p. 101).

Não obstante, seu nível privilegiado de análise é macrossociológico, de maneira que a compreensão das sociedades em transição atentava para os traços mais gerais de suas instituições - as relações sociais de produção, em especial; organizações, por exemplo, o Estado; mas também remetia a grupos - sendo o migrante rural-urbano sua figura característica - e classes sociais, ainda que sua agência fosse quase reativa nas elaborações mais 'duras' (Cardoso; Faletto, 1967).

Embora alguns autores, como Brandão Lopes (1964), ampliassem com frequência esse espectro analítico, transitando até o "nível microssociológico do exame da adaptação do migrante à vida fabril” (Dias, 1974, p. 54), há pouca dúvida de que o enfoque 'adequado' dizia respeito a problemas relacionados à distribuição regional da produção industrial e graus diferenciados de urbanização, à composição da força de trabalho e níveis de emprego, subemprego e desemprego, dentre outros fenômenos investigados via abstração de variações

${ }^{5}$ Naquelas formações conceituais mais sofisticadas, o problema fora resolvido com o recurso a agentes tipicamente coletivos. 
microescalares (Brandão Lopes, 1976).

Indo adiante, a percepção da espontaneidade do processo de desenvolvimento econômico, em sua origem, é complementada pela generalização de formas diversas de "ação consciente e deliberada, no sentido da aceleração do ritmo da mudança do regime econômico" (Costa Pinto, 1972, p. 100), conectando-se ao problema da agência desenvolvimentista. Ainda que muitos dos principais trabalhos não apresentem formulações explícitas acerca do(s) agente(s) privilegiados na indução de processos de desenvolvimento - fato notável dada a estreita relação entre Estado e desenvolvimento na tradição econômica (Leme; Brasil Jr., 2015, p. 495) -, é inegável que a instituição estatal assume relevância especial na corrente.

Dessa forma, a variável 'política' é endógena à compreensão sociológica do desenvolvimento. Nesse registro, Pereira (1970, p. 17) reflete sobre o "planejamento como processo social”, reestabelecendo as conexões do desenvolvimento com a política e a intervenção estatal, suas implicações sobre comportamento político e, principalmente, acerca de seus obstáculos no contexto de uma "estrutura de poder autocrática” (o golpe militar de 1964), da consequente "liquidação das expressões políticas do nacional-desenvolvimentismo" (Pereira, 1970, p. 156) e da conversão a um modelo de desenvolvimento econômico associado.

A decisiva contribuição de Cardoso e Faletto (1967) proporcionou, entretanto, uma perspectiva analítica integrada, econômica e política, do desenvolvimento. Centrada nas assimetrias de poder na sociedade, ela adicionou ^ uma dimensão processual a uma abordagem a predominantemente estrutural. Nesse sentido, oิ a tarefa de "[...] compreender, nas situações es$\therefore$ truturais dadas, os objetivos e interesses que dão sentido, orientam ou animam o conflito entre os grupos e classes e os movimentos sociais que 'põem em marcha' as sociedades em desenvolvimento" (Cardoso; Faletto, 1967, p. 21) tornou-se central na explicação sociológica do desenvolvimento.
Para os autores, isso implicava a própria redefinição do fenômeno, visto "como resultado da interação de grupos e classes sociais que têm um modo de relações que lhes é próprio e, portanto, interesses materiais e valores distintos, cuja oposição, conciliação ou superação dá vida ao sistema socioeconômico" (Cardoso; Faletto, 1967, p. 22). Estruturas socioeconômicas e processos políticos constituem, então, elementos mutuamente influentes, integrando as relações de dependência aos papéis desempenhados por agentes econômicos, sociais e políticos - dentre os quais o Estado desenvolvimentista (Cardoso; Faletto, 1967, p. 108; Costa Pinto, 1972, p. 199).

A integração entre as perspectivas estrutural e processual remete, adicionalmente, a uma abordagem metodológica própria. É possível defini-la de maneira ampla como histórico-estruturalista, explicitando seu parentesco com o pensamento desenvolvimentista latino -americano.

Em primeiro lugar, a noção de estrutura tende a ser apreendida a partir das ideias de interdependência das partes (Costa Pinto, 1972, p. 99) e de totalidade, com vistas tanto a interpretar as transformações inter-relacionadas nas esferas econômica, política e social, no âmbito de sociedades específicas, regionais e (ou) nacionais, quanto a explicitar a interdependência econômica entre as diversas economias nacionais, partindo do enquadramento cepalino.

Em segundo lugar, seu horizonte histórico é o de médio e o de longo prazo. A transformação das estruturas econômicas, sociais e políticas é investigada efetivamente a partir de um escopo temporal largo, permitindo observar modificações sistêmicas nas partes da estrutura e em suas relações, assim como a reconfiguração das posições e dos agentes coletivos que as ocupam. A análise proposta por Cardoso e Faletto (1967, p. 63-67) para o caso brasileiro sintetiza essa temporalidade, ao radicar sua "fase de transição" a uma socioeconomia moderna, em enquadramentos largos da "economia escravocrata”, e tipo de “dominação 
patrimonialista”, passando pela "economia exportadora" e pela "dominação oligárquica”, e chegando à crise dessa última, sua solução revolucionária em 1930, e a consequente liberação do processo de industrialização nacional.

Não coincidentemente, a escala de análise adotada predominantemente pela tradição sociológica de estudos sobre o desenvolvimento foi a nacional, apoiada no postulado da complementaridade dos processos de desenvolvimento e subdesenvolvimento - isto é, das conexões causais entre os planos externo e interno.

Nesse sentido, embora suas aplicações mais sofisticadas fossem sensíveis ao âmbito internacional do desenvolvimento, sendo assim, "óbvia a necessidade de ligar tais fenômenos a processos e sistemas, econômicos e sociais, que são mundiais no seu escopo" (Brandão Lopes, 1976, p. 20-21), sua perspectiva permaneceu metodologicamente nacionalista, incapaz de articular processos em múltiplas escalas.

\section{A ANTROPOLOGIA DO DESENVOLVI- MENTO DA APAD}

Um recorte não exaustivo da bibliografia em língua portuguesa dedicada à discussão no campo da antropologia do desenvolvimento (Schröder, 1997; Baré, 2004; Radomsky, 2011; Carneiro, 2012; Schröder, 2014) apresenta um cenário bastante diferente. Vista como uma subdisciplina seja "em vias de se formar" (Schröder, 1997, p. 91), seja diante de "um momento de estagnação” (Schröder, 2014, p. 1), sua origem alude a vínculos mutuamente constitutivos entre as posições analítica e normativa.

Em âmbito normativo, o esforço de reconstrução do período posterior à $2^{\text {a }}$ Guerra Mundial demarca a emergência de um mercado de trabalho especializado para o desenvolvimento, o qual seria atravessado por uma primeira crise na década de 1960 (Carneiro, 2012, p. 131). Seu "renascimento nos anos 1970" (Carneiro, 2012, p. 131) articulava, então, uma contratura nos mercados acadêmico e museológico frente à reestruturação da ajuda externa norte-americana, que se refletia na maior "disposição de muitos antropólogos para trabalhar para órgãos governamentais” (Escobar, 1997, p. 499; Schröder, 1997, p. 84). Embora ainda pouco numerosos e atuando em projetos em escala local (Schröder, 2014, p. 8), esses pioneiros ajudaram a difundir uma concepção distintamente normativa do desenvolvimento, i. e. "um bem cujos efeitos positivos [deviam] ser divididos com as populações mais desprovidas" (Carneiro, 2012, p. 131).

A partir dos anos 1980, a proliferação de programas de cooperação internacional havia dado azo a consequências radicalmente diversas daquelas previstas e fortalecia correntes críticas (Radomsky, 2011, p. 75). Sua expressão máxima emergiria com os trabalhos de Escobar (1991, 1995, 1997) e Ferguson (1990, 1999), cujas abordagens concediam primazia à linguagem e ao discurso na desconstrução crítica da "própria noção de desenvolvimento" (Carneiro, 2012, p. 132). Não obstante, essa 'virada discursiva' tendia a produzir uma idealização substituta, instituindo uma oposição entre a chamada "antropologia para o desenvolvimento" e uma "nova' "antropologia do desenvolvimento"6 (Escobar, 1997, p. 498). Sua compreensão em termos de pós-desenvolvimento (Escobar, 1995, p. 212-226; Radomsky, 2011; Schröder, 2014, p. 11) remetia ainda, de modo problemático, à reunião de "experiências realizadas por grupos sociais autônomos, a partir de situações locais isoladas da lógica do capital e da ação estatal" (Carneiro, 2012, p. 133).

Mais importante: a referida contraposição deixava de fora expressões-chave da renovação desse subcampo, em particular uma tradição emergente em torno da obra de De Sardan (1995, 2005) e da Associação Euro-Africana para a Antropologia da Mudança Social e

${ }^{6}$ A referida oposição se sobrepunha e atualizava uma outra, a saber, "entre a antropologia "básica", "abstrata", "pura", "acadêmica”, e a outra, "aplicada”, "prática” e "suja” (quer dizer, comprometida)", nos termos de Schröder (1997, p. 90). 
o Desenvolvimento (APAD). Nesse sentido, uma apreciação crítica de suas contribuições é não apenas relevante para uma reconstituição fidedigna do próprio subcampo, ${ }^{7}$ mas tende a estimular pontos de contato com a sociologia.

No que diz respeito à definição de uma unidade de análise, Schröder (1997, p. 92) acredita que a antropologia do desenvolvimento pouco avançou em relação a uma "visão muito restrita [...] que só fala de empenhamentos no âmbito de projetos". Essa perspectiva se vincula às práticas profissionais referentes à gênese do campo e ao seu ethos (Schröder, 2014, p. 8). Nesse sentido, a ênfase na investigação de "práticas sociais efetivamente utilizadas no contexto de um projeto de desenvolvimento" (De Sardan, 2005, p. 30) constitui seu núcleo heurístico (Elwert; Bierschenk, 1988; Bierschenk et al., 2002), conferindo à noção de 'projeto' o traço de um "tipo ideal da operação de desenvolvimento" (Bierschenk et al., 2002, p. 4).

A referência a uma unidade desse tipo concerne a um nível de análise microssociológico, privilegiando interações face a face e enfocando "o jogo de atores em configurações desenvolvimentistas concretas" (Carneiro, 2012). Embora essa "análise da micropolítica" ou em "micronível" (Schröder, 1997, p. 96) tenha avançado uma compreensão acionalista oै dos processos de desenvolvimento, caracteri: zando, de modo geral, todo o subcampo, "este

\& em combinar pesquisa situada e análise geral,

จิ "uma arena [...] é um lugar de confrontações

concretas [...][e] se refere a um espaço 'local”" (De Sardan, 1995, p. 234). A arena como espaço de interação entre grupos estratégicos

${ }^{7}$ Uma análise competente da posição desta obra no campo da antropologia do desenvolvimento foi realizada por Carneiro (2012) e a publicação recente de um dossiê sobre a obra do autor (Gomes, Faure e Meneses, 2015) dá mostras de sua penetração e relevância no debate brasileiro. heterogêneos, possuidores de diferentes níveis de poder (De Sardan, 2005, p. 186), remete, portanto, a um nível analítico 'mais concreto', tipicamente local - não referido seja "à política nacional, nem à internacional [...] [nas quais] ‘desenvolvimento' ou é um termo retórico ou um posicionamento político-econômico" (De Sardan, 2005, p. 184).

Nesse sentido, Cesarino (2014, p. 21) defende que a chamada "problemática da escala está no cerne da constituição da disciplina antropológica enquanto tal”, relacionando-se intimamente com o método etnográfico, inicialmente formulado a partir da observação de "pequenas comunidades face a face" e "segundo o modelo malinowskiano do antropólogo solitário". Modelos alternativos vêm, entretanto, enfocando fenômenos que transcendem a localidade em termos de exercício etnográfico multissituado (Marcus, 1995) ou mesmo global (Burawoy, 2000). Dentre suas possibilidades, investigações coletivas de um mesmo objeto e o rastreamento de seu movimento em diversos pontos de uma trajetória (Knowles, 2014) aparecem como contrapontos úteis na reconciliação entre método e objeto translocal.

Para Schröder (1997, p. 93), a definição do desenvolvimento como objeto de pesquisa seria ainda mais problemática, de modo que "em quase todos os textos da antropologia do desenvolvimento, o conceito do 'desenvolvimento’ não é explicitado” (Schröder, 2014, p. 3). Não obstante, em muitos dos trabalhos de autores ligados à APAD, essa imprecisão é resolvida. Desse modo, o desenvolvimento é definido como a totalidade "dos processos sociais induzidos por operações voluntaristas de transformação de um meio social, empreendidos por meio de orientação de instituições ou atores exteriores a esse meio, e que se baseiam no transplante de recursos e/ou técnicas e/ou saberes” (De Sardan, 2005, p. 24-25). Essa corrente definiu, assim, um "programa de investigação [centrado no] exame aprofundado dos processos de mudança socioeconômica e política” (Carneiro, 2012, p. 133). 
Nessa vertente, a mudança é tipicamente planejada, e o lócus das práticas de planificação é exógeno à escala local na qual são observados seus efeitos. Desse modo, a definição enfoca, de um lado, a problemática do agente indutor do desenvolvimento, enquanto realça uma divisão entre o interno e o externo que reproduz e complementa a bifurcação local e translocal no plano da escala de análise, de outro.

Da perspectiva da agência, são desconstruídos os discursos centrados em agentes indutores paradigmáticos, como o Estado, por exemplo, em favor de um "universo largamente cosmopolita de experts, de administradores, de responsáveis por ONGs, de pesquisadores, de técnicos, de chefes de projetos, de agentes de campo, de intermediários, de animadores de grupos ou de associações" (De Sardan, 2005, p. 25), incorporando, consequentemente, uma orientação pluralista. É problemática, entretanto, a virtual ausência de referências a agentes econômicos. Essa característica reflete, assim, as fronteiras empíricas de grande parte das pesquisas que informam a abordagem, atualizada como uma "socioantropologia dos espaços públicos africanos" (Carneiro, 2012, p. 145), assim como a centralidade dos projetos de cooperação internacional. ${ }^{8}$

Embora se reconheça que a antropologia política e seu enfoque na investigação do "poder em nível local” (De Sardan, 2005, p. 33) constituem uma de suas matrizes, análises críticas sugerem afinidades mais fortes, defendendo que "os conceitos aplicados na antropologia do desenvolvimento não foram criados dentro deste ramo da disciplina, mas emprestados de [...] subdisciplinas [...] [como a] antropologia política” (Schröder, 1997, p. 94). De fato, os conceitos gerais de arena, estratégia e poder são exógenos à abordagem, assim como a própria visão do desenvolvimento como um "campo político" (Schröder, 2014, p. 5) reforça essa percepção.

${ }^{8}$ Mais que o 'projeto de desenvolvimento', essa literatura tende a instituir o 'projeto de cooperação para o desenvolvimento' como a unidade analítica básica do desenvolvimento, de modo que a descentralização da agência na abordagem permanece aquém de sua promessa includente.
Não obstante, a ideia-força do desenvolvimento como arena dá relevo a estruturas de relações entre "atores sociais [que,] no mesmo palco, se confrontam acerca de questões de poder, influência, prestígio, notoriedade e controle” (De Sardan, 2005, p. 71), de modo que o enfoque analítico nas relações de poder converte o conflito social em expressão concreta do desenvolvimento e sua principal "porta de entrada" (Carneiro, 2012, p. 134).

Em realidade, esse conjunto de elementos diz respeito a um enfoque teórico de matriz interacionista. Atribui-se, assim, atenção singular “à dinâmica das lógicas sociais presentes nas situações de interação em que se desenrolam as ações de desenvolvimento" (Carneiro, 2012, p. 133). A própria noção de arena é distintamente interacionista, em contraposição ao conceito de campo, como assinala Carneiro (2012, p. 143). O espaço social é representado, dessa forma, "em um sentido mais imediato no qual os atores possuem algum tipo de consciência das disputas que se desenrolam em seu interior" (Carneiro, 2012, p. 143). Nas palavras do autor:

Não é possível evitar análises mais específicas, mais intensivas e mais próximas das interações sociais reais. É aí onde intervém, ou deveria intervir, a socioantropologia. O 'ponto de impacto' das políticas de desenvolvimento sobre as populações envolvidas, em outras palavras, o espaço social onde se dá a interação entre operações de desenvolvimento (projetos ou ações) e 'públicos-alvo' é, nesse sentido, um nível estratégico de investigação, ao qual o trabalho de campo antropológico intensivo é particularmente adaptado (De Sardan, 1995, p. 16).

Essa perspectiva revela uma identificação problemática entre processos interativos face a face e 'realidade'. Nesse sentido, Carneiro (2012, p. 144) recupera a crítica bourdieusiana à abordagem dos fenômenos econômicos a partir de redes sociais e do estabelecimento arbitrário de relações de copresença como fundamento 'realista' de estruturas sociais e alternativa à dicotomia ação e estrutura. Nesse sentido, a seção subsequente realiza uma incursão empírica em projetos de mineração de 
larga escala e no processo de desenvolvimento da Amazônia Oriental, com o objetivo de problematizar a 'realidade' subjacente às interações face a face e sua abordagem uniescalar.

\section{MINERAÇÃO E DESENVOLVIMENTO NA AMAZÔNIA ORIENTAL}

\section{Multiescalaridade e ação econômica nos projetos PFC e PFC S11D da Vale}

As raízes institucionais da Companhia Vale do Rio Doce (CVRD) remontam ao nacional desenvolvimentismo (Triner, 2011). Desde os anos 1960, no entanto, a empresa vem se transformando a partir da adoção de uma orientação exportadora transoceânica (Vale, 2012, p. 110-112), intensificada a partir da privatização em 1997 e chegando ao paroxismo nos anos 2000, sob a conjuntura do boom das commodities (Prates, 2007).

Sediada no Brasil, as ações da agora Vale S. A. (Vale), segunda maior mineradora diversificada do globo, aparecem listadas em alguns dos maiores mercados de capitais do mundo, e suas operações extrativas abrangem países da África, Américas, Ásia e Oceania, impulsionando uma receita operacional líquida de US\$ ํ. 25,6 bilhões em 2015 (Vale, 2016, p. 91-2). No ํ. mesmo ano, empregava 74,1 mil trabalhadores, estabelecendo negociações coletivas com sindicatos da Austrália, Brasil, Canadá, Indoi nésia, Malaui, Moçambique, Nova Caledônia, Peru e Reino Unido (Vale, 2016, p. 139).

Essa metamorfose em uma corporação transnacional (CTN) (Dicken, 2011) é, no en$\dot{A}$ tanto, condicionada ao acesso privilegiado à ơ maior reserva de minério de ferro do mundo, a Província Mineral de Carajás ${ }^{9}$ (Vale, 2012, p. 161; Minérios \& Minerales, 2011; Hildebrand; Sampaio, 2001, p. 78). Seus recursos foram

${ }^{9}$ Levantamentos geológicos entre 1970 e 1974 revelaram reservas de 17,9 bilhões de toneladas com teor médio de $66,1 \%$ de ferro. A província compreende ainda depósitos expressivos de cobre, cromo, estanho, manganês, níquel, ouro e tungstênio. descobertos em 1967 pela Companhia Meridional de Mineração S. A. (CMM), subsidiária da então líder do mercado siderúrgico mundial, a United States Steel Co. (US Steel) (Treece, 1987; Monteiro et al., 2006) e, a despeito de seu direito preferencial (Treece, 1987, p. 12), a concessão para exploração das reservas se daria apenas dois anos depois (Vale, 2012, p. 161), seguida pela criação de uma joint venture entre a CMM (49\%) e a CVRD (51\%), a Amazônia Mineração S.A. (AMZA), em 1970.

As concepções estatais de controle e intervenção econômica diretos foram ainda reforçadas a partir da aquisição da CMM pela CVRD em 1977 - alijando a US Steel (Monteiro et al., 2006, p. 417; Vale, 2012, p. 164-165). Emergia, assim, o Projeto Ferro Carajás (PFC), um "megaprojeto" de exploração mineral, beneficiamento primário e exportação (Oliveira, 2011, p. 137). Em 1981, ocorria a primeira detonação para a abertura da mina $\mathrm{N}^{2} \mathrm{E}^{10} \mathrm{em}$ Parauapebas (PA) (Vale, 2013, p. 22); em 1985, entrava em operação a Estrada de Ferro Carajás (EFC); ${ }^{11}$ e, finalmente, o primeiro embarque de minério para o porto de Oita (Japão) foi realizado via terminal privativo localizado no Porto de Itaqui, São Luís (MA) (Santos, 2010, p. 120). A partir do estabelecimento de uma coalizão de interesses estatais e de capitais siderúrgicos multinacionais, o PFC configuraria a indústria extrativa mineral como o evento indutor da mudança social do território oriental amazônico a partir dos anos 1980, implantando as infraestruturas de extração, estocagem, beneficiamento primário e transporte - ferroviário e marítimo - do minério de ferro, e adensando a rede global de produção (RGP $)^{12}$ (Henderson et al., 2011, p. 153) da Vale (San-

${ }^{10}$ O Sistema Norte compreende as áreas de mineração N4E, N4W, N5E, N5W e N5S.

${ }^{11}$ A EFC atravessa 23 municípios (19 no Maranhão e 4 no Pará) ao longo de $892,5 \mathrm{~km}$, possuindo estações de embarque em Parauapebas e Marabá (PA) e Açailândia, Santa Inês e São Luís (MA).

${ }^{12} \mathrm{O}$ conceito de RGP se refere a complexos funcionais e geograficamente dispersos de operações corporativas em rede através das quais bens e serviços são produzidos, distribuídos, consumidos e descartados, podendo ser operacionalizado em níveis corporativo, setorial e territorial. 
tos; Milanez, 2015a, 2015b). O projeto instituiu, assim, a região em um nó de RGPs mínero-siderúrgicas; redes de recursos, cf. Wilson (2013).

De um lado, as condições macroeconômicas nacionais abarcam esse processo de conversão funcional. Diante da escalada da dívida externa (Coelho, 2015, p. 31) e dos desequilíbrios estruturais do Balanço de Pagamentos brasileiro nos anos 1980, entrava em cena uma estratégia de crescimento via recursos naturais, acoplando a Amazônia Oriental ao processo de internacionalização econômica centrado no Sudeste, e a reconstituindo como uma economia regional extrativa (Bunker; Ciccantell, 2005).

De outro, o padrão de financiamento do PFC assume centralidade analítica, integrando agentes que operam em escalas nacional, mesorregional e global. A CVRD investiu US\$ 852 milhões no PFC, enquanto o Banco Nacional de Desenvolvimento Econômico (BNDES) forneceu US\$ 1,02 bilhão. Dessa forma, essas e outras fontes nacionais atingiram US\$ 1,872 bilhão, ou 51,4\% do capital total de US\$ 3,642 bilhões (Monteiro et al., 2006, p. 424). Mais importante: o apoio estatal permitiu à empresa obter financiamentos externos que chegaram a US $\$ 1,77$ bilhão com destaque para os da European Coal and Steel Community (ECSC), no valor de US\$ 600 milhões; da Nippon Carajás Iron Ore Co., Ltda. - um consórcio composto por algumas das principais corporações siderúrgicas e financeiras japonesas -, de US\$ 500 milhões; do Banco Internacional para Reconstrução e Desenvolvimento (BIRD), da ordem de US\$ 304,5 milhões; e do alemão Kreditanstalt fur Wiederaufbau (KfW), tendo atingido US\$ 122,5 milhões (Treece, 1987; Monteiro et al., 2006).

De um lado, a expressiva participação do Japão no financiamento do PFC deve ser compreendida à luz do lançamento de seu programa de desenvolvimento com importações (kaihatsu yunyu) em fins dos anos 1950 (Frattolillo, 2012; Wilson, 2013). O programa visava reduzir impactos ambientais e desequilíbrios comerciais e, principalmente, ampliar a oferta e o acesso a minerais siderúrgicos ${ }^{13}$ (Treece, 1987, p. 9), promovendo novos projetos extrativos no exterior (Wilson, 2013, p. 52-3). De outro, a revisão parcial da estratégia brasileira de desenvolvimento por substituição de importações no início dos anos 1970 facilitou as condições de incorporação do Brasil nas "redes de recursos da Ásia-Pacífico” (Wilson, 2013, p. 105), permitindo o estabelecimento de vínculos entre Brasil e Japão em projetos minerais e siderúrgicos desde os anos 1970, sobretudo no PGC e no PFC.

Essa recuperação do padrão de financiamento do PFC remonta, em realidade, à emergência de um novo evento indutor da mudança social no território oriental amazônico, na medida em que o Projeto Ferro Carajás S11D (PFC S11D ${ }^{14}$ ) constitui o maior startup mineral da história humana, com 90 milhões de toneladas por ano (Mtpa) (Vale, 2013, p. 12).

A estratégia de investimento centrada no PFC S11D deve, no entanto, ser compreendida à luz dos cenários do boom e do pós-boom das commodities. Ao longo do primeiro, estratégias de acesso preferencial a recursos minerais dirigidas pelo Estado chinês e sua indústria siderúrgica (Wilson, 2012) e de investimento de CTNs mineradoras (Carvalho et al., 2014, p. 210-11) convergiram para a formação de sobrecapacidade crônica e excesso de oferta, expressas na redução generalizada dos preços das commodities minerais ou pós-boom. O novo cenário compreende um horizonte de longo prazo, além de problemas de endividamento e resultados operacionais e financeiros declinantes para as empresas (Nieponice et al., 2015).

13 Estratégias nacionais e, principalmente, macrorregionais foram igualmente significativas no envolvimento da ECSC no PFC, incorporando mecanismos de financiamento e contratos de longo prazo com países como a Alemanha Ocidental e a Itália.

${ }^{14}$ A denominacão remete à localização de reservas no bloco D do corpo geológico S11, Serra Sul. Segundo a corporação, "o potencial mineral do corpo S11 é de 10 bilhões de toneladas de minério de ferro, sendo que o bloco D, isoladamente, possui reservas provadas e prováveis de 4,24 bilhões de toneladas métricas" (Vale, 2013, p. 12). O PFC S11D deve ampliar a capacidade do Sistema Norte para $230 \mathrm{Mtpa}$. 
Em comum, no entanto, ambos contribuem para o aprofundamento da estrutura oligopólica do segmento ferrífero. ${ }^{15}$ Nesse sentido, "os maiores [agentes] do mercado apostam em produzir o máximo possível mesmo com os preços baixos” (Royle, 2015). A Vale opta, dessa forma, pela reconcentração em seu segmento-chave, o minério de ferro, assim como pela ampliação de capacidades extrativa e logística. A grandiosidade e o potencial de transformação estrutural do PFC S11D devem, portanto, ser apropriadamente entendidos, em contextos macro e microssociológico, a partir da autopercepção do caráter "estratégico para a Vale manter sua posição de liderança no mercado global" (Vale, 2013, p. 12).

As principais infraestruturas do projeto compreendem: i) o implante da nova mina e de uma unidade de beneficiamento primário, essa última localizada no interior da Floresta Nacional de Carajás, em Canaã dos Carajás (PA); ii) sua ligação ao km 858 da EFC em Parauapebas (PA) ao longo de 101,1 km, por meio do Ramal Ferroviário Sudeste do Pará (Faustino; Furtado, 2013, p. 51); iii) a ampliação de capacidade de movimentação ao longo de $504 \mathrm{~km}$ da EFC, com a "remodelação de [226 km] de linhas existentes" (Vale, 2013, p. 7); isso significa, na prática, sua duplicação; e iv) a amplia: ção da capacidade operacional de seu terminal ‥ privativo em São Luís (MA).

Estima-se que o valor total do investimento atinja US\$ 19,67 bilhões, e a fase operacional gere "3.600 postos permanentes de trabalho na região" (Vale, 2013). ${ }^{16} \mathrm{O}$ aprofundamento de sua natureza capital intensiva remete à adoção de tecnologias de beneficiamento primário e transporte interno que prescindem de caminhões fora de estrada (Vale, 2013, p. 42).

Desde seus primeiros sinais em 2004 (Ribeiro, 2004), o financiamento público do

${ }^{15}$ As quatro maiores CTNs do subsetor, Vale, BHP Billiton plc., Rio Tinto plc. e Forstescue Metals Group controlaram $71 \%$ das vendas da commodity em 2014, e devem ampliar essa participação para $80 \%$ até 2018.

${ }^{16}$ A empresa estimou a geração de 3.100 empregos diretos e 9.800 indiretos no Pará em sua fase de implantação. empreendimento foi visto como determinante ${ }^{17}$ (Bndes, 2008). Desse modo, o BNDES aprovou o empréstimo de R\$ 3,9 bilhões (US\$ 1,92 bilhão) para o projeto Capacidade Logística Norte (CLN 150 Mt.) em 2012, em apoio ao PFC S11D (Durão e Rosas, 2012), assim como um financiamento de R\$ 6,2 bilhões em 2014, destinado aos projetos PFC S11D, Carajás Adicional 40 Mt. e CLN 150 Mt. (Saraiva, 2014).

De outro lado, a Vale vem reiteradamente apontando a necessidade de levantar recursos junto a instituições de crédito internacionais, referindo-se ao Japan Bank for International Cooperation (JBIC) (Durão e Góes, 2012), ao KfW (Borges; Góes, 2013) e ao Export Development Canada (EDC), com o qual contratou linha de financiamento de US\$ 775 milhões para a importação de bens e equipamentos (Góes, 2014).

A despeito das reminiscências do PFC, a baixa diversidade dos agentes externos, a efetividade e o volume do financiamento contratado, assim como a ausência das trading companies japonesas, apontam para um cenário distinto, no qual a própria corporação adquiriu margem de atuação independente, fazendo uso do fluxo de caixa e de capacidades de obtenção de recursos via emissão de títulos (Durão; Góes, 2012). Já em 2014, a empresa havia emitido "R\$ 1 bilhão em debêntures de infraestrutura" (Saraiva, 2014) com vistas à implantação do novo ramal ferroviário (Góes, 2014).

Isso não significa, no entanto, que a corporação seja autônoma no que diz respeito à obtenção de recursos externos. Em particular, a depressão dos preços no pós-boom vem afetando seus resultados operacionais e seu fluxo de caixa - perdendo cerca de 1/3 de sua receita operacional líquida entre 2014 e 2015 (Santos; Milanez, 2015b). Por sua vez, o desempenho setorial consistentemente negativo quanto à

17 O Estado brasileiro tem sido um ‘parceiro' no desenvolvimento da corporação. Em particular, a agressiva estratégia de mercado da Vale, nos anos 2000, foi decisivamente apoiada pelo BNDES. Em 2008, por exemplo, a empresa obteve a concessão do limite de crédito de $\mathrm{R} \$ 7,3$ bilhões para apoio às atividades do seu programa de investimento 2008/2012 no Brasil. 
distribuição de retorno ao acionista parece vir produzindo um efeito de "perda de apetite" (Nieponice et al., 2015, p. 4) dos investidores, acentuado no caso da Vale por processos complementares de rebaixamento de suas notas de investimento por agências de classificação de risco (Leahy, 2015), especialmente após a ruptura da barragem de rejeitos da Samarco Mineração S.A. em Mariana (MG), sua controlada parcial, em 2015 (Poemas, 2015).

\section{Grandes projetos, desenvolvimento e agen- tes sociais na Amazônia Oriental}

O PFC e o PFC S11D constituem propriamente grandes projetos de investimento (GPIs), no sentido atribuído por Vainer (1990); ou projetos de infraestrutura de grande escala (PGEs), na formulação de Ribeiro (1987, 2008). Entendidos como expressões extremas do desenvolvimento econômico (Ribeiro, 2008, p. 111), mobilizam e mercantilizam volumes expressivos de dinheiro (capital), bens naturais (recursos) e seres humanos (trabalhadores e atingidos), induzindo processos de mudança social estrutural, i. e., 'grandes transformações' (Polanyi, 2000, p. 94).

Nesse sentido, GPIs e PGEs apontam questões críticas quanto à definição de unidades de análise apropriadas a investigações socioantropológicas sobre o desenvolvimento. Enquanto 'pequenos' projetos ou planos de desenvolvimento local modificam interações face a face entre agentes individuais e (ou) coletivos, redefinindo seus recursos e formas de mobilização, GPIs e PGEs adicionam uma dimensão exclusiva da mudança social.

Essa dimensão diz respeito a uma inflexão das estruturas sociais a partir da qual objetos mutáveis predominam sobre os componentes de estabilidade na experiência cotidiana de homens e mulheres, em um dado território, e impõem um risco, potencial ou efetivo, econômico e cultural, à reprodução das formas 'tradicionais' de vida e de trabalho. Nesse sentido, o comprometimento da reprodução intergeracional de pescadores artesanais, ribeirinhos, quilombolas, indígenas, etc., mediante o cerceamento de seus espaços sociofísicos, e sua passagem forçada à condição de assalariados, subempregados ou desempregados urbanos constitui um de seus traços elementares.

A ocupação da Amazônia Oriental, que correspondia a uma dinâmica de acumulação de capital baseada nos setores agropecuário e madeireiro até os anos 1980, seria transformada radicalmente com a implantação do PFC, que estabeleceria condições efetivas para a (re) criação e integração dos mercados de terra e de trabalho em escala regional, determinando ainda a formação de novos mercados setoriais - em especial, a produção de ferro gusa. ${ }^{18}$

De fato, a criação da infraestrutura logística e a oferta de minério de ferro, combinadas ao apoio decisivo de políticas de atração de investimento industrial ${ }^{19}$ (Monteiro, 2004, p. 3), determinaram o implante da indústria de ferro gusa de mercado na região. Esse parque, hoje parcialmente inativo, conta atualmente com 18 firmas e 40 altos-fornos no Maranhão e no Pará (Assis; Carneiro, 2012, p. 248), dirigindo cerca de $80 \%$ de sua produção ao mercado norte-americano - em particular à Nucor Co. (Santos, 2010, p. 150).

Considerando a centralidade do carvão vegetal na produção guseira nacional (Ferreira et al., 2006, p. 6) e seu impacto sobre a mata nativa oriental amazônica, o PFC constituiu o evento crucial na conformação desse território como um nó adversamente incorporado à rede global de produção do aço, através de formas de trabalho análogas à escravidão, do trabalho infantil e de relações assalariadas precárias (Phillips; Sakamoto, 2012; Phillips et al., 2014;

${ }^{18} \mathrm{O}$ ferro gusa, um bem intermediário empregado por usinas siderúrgicas semi-integradas, é tipicamente uma commodity, i. e., um bem homogêneo, cujos preços são definidos internacionalmente.

${ }^{19}$ Recursos públicos através do Fundo de Investimentos do Nordeste (FINOR) e do Fundo de Investimentos da Amazônia (FINAM) compuseram até $75 \%$ do investimento na formação de áreas florestais e industriais nos projetos aprovados. 
Mcgrath-Champ et al., 2015).

Nesse sentido, GPIs e PGEs tendem a explicitar "níveis de integração locais, regionais, nacionais, internacionais e transnacionais [...] [vinculando] áreas relativamente isoladas a sistemas mais amplos de mercados integrados" (Ribeiro, 2008, p. 111-112). Em grande medida, essa unidade de análise impõe a supressão de escalas privilegiadas na discussão do desenvolvimento em favor de abordagens multiescalares - apreendidas com alguma eficácia por meio de redes (Ribeiro, 2008; Henderson et al., 2011).

Essa perspectiva possui ainda implicações metodológicas para as abordagens predominantes da questão, premidas seja pelo nacionalismo metodológico, seja pelas formas tradicionais da pesquisa etnográfica. A subseção anterior foi dedicada a descrever o PFC e o PFC S11D a partir de suas dimensões econômica e política, de modo a esboçar condicionamentos em escalas múltiplas e interativas, articulando uma estratégia nacional de crescimento centrada em recursos via corporação estatal, posteriormente convertida em CTN 'verde-e-amarela' (Bossi et al., 2009), a estratégias estatais e privadas nacionais (Japão) e mesorregionais (UE) de acesso privilegiado a esses recursos.

Não obstante, GPIs e PGEs representam feixes de relações sociais extremamente complexas, cujo entendimento, no nível microssociológico, permanece tão central quanto aquele relacionado ao que Knowles (2014, p. 290) define criticamente como "principais estradas ou vias", propondo uma compreensão mais sofisticada da interseção entre as "estradas secundárias e principais" do fenômeno da globalização (Knowles, 2014, p. 303).

Se, de um lado, modelos macrossociológicos 'colonizaram' sua investigação, assim como a sociologia o fez com o desenvolvimento econômico, negligenciando o quadro analítico da vida cotidiana (Knowles, 2014, p. 291) e suas implicações para o mundo da reprodução social e modos específicos por meio dos quais 'grandes' riscos são transferidos "para as condições pessoais" dos indivíduos e suas famílias (Knowles, 2014, p. 306), de outro, não é menos notório que fenômenos como a globalização e o desenvolvimento tenderam a ser subteorizados ou empregados como pano de fundo em boa parte das interpretações microssociológicas da vida cotidiana.

Dessa forma, enveredar pelas jornadas de crianças, trabalhadores 'escravizados', camponeses expropriados, mulheres exploradas sexualmente, trabalhadores na mineração, indígenas e quilombolas, assim como engenheiros, acionistas, etc. e suas famílias, apreendendo-as como "sequências episódicas e contínuas de movimentos" capazes de revelar seus "mundos sociais" (Knowles, 2014, p. 294) surge como uma tarefa-chave, ainda que pouco explorada, nas investigações sobre o desenvolvimento.

Nesse sentido, quanto ao nível de análise e abordagem metodológica, o fenômeno do desenvolvimento demanda formas híbridas e perspectivas multimétodos. Jornadas de homens migrantes e de meninas e mulheres jovens, por exemplo, se imbricam no PFC S11D em municípios como Açailândia (MA), expressando-se de maneira dramática em "um crescente número de crianças e adolescentes ficando grávidas de homens que não moram aqui, que fazem os meninos e vão embora" (representante do CDVDH, apud Faustino; Furtado, 2013, p. 64). Nesse sentido, análises de trajetória de vida e trabalho podem constituir um complemento essencial a discussões macrossociológicas sobre padrões de migração extremamente sensíveis a períodos de implantação de empreendimentos infraestruturais (Carneiro, 1997, p. 238-9).

Da perspectiva do enfoque analítico, investigações sobre desenvolvimento necessitam igualmente atentar para seus aspectos 'fenomênicos', de modo que processos de industrialização, de urbanização, mas também de migração, proletarização, dentre outros, permanecem constitutivos da questão. Não obstante, processos sociais, i. e., mudanças amplas e 
ininterruptas, implicando permanência no tempo (Elias, 2006, p. 27-28), remetem tanto a estruturas quanto à ação, sendo produzidos e atualizados no plano das relações sociais. Nesse sentido, mesmo formulações complexas quanto ao tratamento da política e dos grupos sociais na sociologia (Cardoso; Faletto, 1967; Pereira, 1970) pouco contribuíram para evidenciar os modos específicos pelos quais múltiplos agentes configuram relações de poder incessantemente em processos de desenvolvimento.

Isto não significa, no entanto, circunscrever o desenvolvimento à política e a padrões específicos de relações, mas dar expressão a capacidades multidirecionais de exercício do poder e, consequentemente, discernir uma perspectiva multiagência. De fato, como aponta De Sardan (2005), o desenvolvimento implica a formação de arenas, ainda que elas não sejam especificamente locais - particularmente no que respeita a GPIs e PGEs.

Enquanto o PFC S11D vem provocando processos de desterritorialização de comunidades como a Colônia do Sol Nascente e a Vila Mozartinópolis, em Canaã dos Carajás (PA), implicando táticas de rebaixamento dos custos indenizatórios via negociação individual (Coelho, 2015, p. 65), assim como inúmeros impactos $^{20}$ (Treece, 1987; Carneiro, 1994; 1997; Monteiro et al., 2006; Oliveira, 2011; Assis; Carneiro, 2012; Faustino; Furtado, 2013; Coelho, 2015) sobre as áreas adjacentes ao complexo mina-usina-ferrovia-porto, reações de múltiplos agentes, em escala local, vêm questionando o exercício de poder corporativo e institucional, por exemplo, através da ocupação da sede da Prefeitura Municipal de Parauapebas, núcleo ocupacional do PFC e área estratégica de controle territorial para a Vale (Piquet, 1998), com vistas à "legalização de suas casas e terrenos e por [melhorias na oferta de] serviços públicos" (Coelho, 2015, p. 134).

De modo importante, processos localizados e deslocalizados parecem ter assumido

${ }^{20}$ A descrição e análise dos impactos provocados pelo PFC e do PFC S11D fogem ao escopo do texto. centralidade no que respeita à Vale e ao PFC S11D. Nesse sentido, agentes sociais diversificados têm empregado táticas de "disrupção de atividades operacionais" dirigidas à EFC (Santos; Milanez, 2015a, p. 762) nas múltiplas localidades em que ela se enraíza materialmente, espelhando formas organizacionais em rede. Objetivando influenciar o engajamento da empresa em negociações e (ou) reforçar compromissos previamente assumidos por ela, tais ações de interrupção se intensificaram a partir do início da duplicação, tendo atingido quinze episódios em 2015 (Almeida, 2015).

Avançando o tópico da multiescalaridade da agência social, Santos e Milanez (2015a, p. 762) identificaram ainda que alguns dos principais agentes e suas estratégias de contestação na RGP do minério de ferro operam em escala transnacional. Os autores enfatizam, assim, a consolidação de redes como a Articulação Internacional dos Atingidos pela Vale (AIAV), que integra movimentos sociais e trabalhadores em diferentes países da África, Américas e Oceania, e seu foco em táticas de influência direta sobre investidores, agindo como "acionistas críticos" em assembleias, assim como indiretamente, buscando atuar sobre a opinião pública através de crítica reputacional.

Tais exemplos colocam em questão abordagens com foco quase exclusivo em agentes privilegiados, sejam eles o Estado nacional, agências de cooperação internacional ou mesmo CTNs - pouco exploradas nas análises sociológicas e antropológicas do desenvolvimento, mas quase onipresentes no campo da economia política internacional (Dicken, 2011; Henderson et al., 2011). Embora o agente econômico, de modo mais geral, tenha assumido centralidade heurística na compreensão do desenvolvimento econômico a partir da globalização, é apenas à medida que ele se relaciona com outros agentes, econômicos e não econômicos, e induz a mudança social, que processos de desenvolvimento se materializam. De fato, uma abordagem propriamente socioantropológica do tema demanda uma perspectiva 
multiagência, capaz de dar conta dos

[...] vários segmentos de populações locais (elites locais e líderes de movimentos sociais, por exemplo); empresários privados, funcionários e políticos em todos os níveis de governo; pessoal de corporações nacionais, internacionais e transnacionais (diferentes tipos de empreiteiros e consultores, por exemplo); e pessoal de organizações internacionais de desenvolvimento (funcionários de agências multilaterais e bancos regionais, por exemplo) (Ribeiro, 2008, p. 110).

Nesse sentido, o desenvolvimento econômico, entendido como manifestação específica e extrema da mudança social, apresenta-se como um processo cumulativo e irreversível, fundado em interações mutuamente condicionantes entre transformações econômicas e sociopolíticas. Por conseguinte, é absolutamente crucial apreender o desenvolvimento a partir de suas dinâmicas empíricas contemporâneas, grandemente influenciadas por mercados e CTNs, mas, ao mesmo tempo, estruturadas por formas não econômicas e cotidianas de agência, o que permite explicar tanto as condições de emergência quanto as de reprodução da mudança social e do conflito em processos desenvolvimentistas.

\section{CONSIDERAÇÕES FINAIS}

A discussão apresentada se inscreve em uma 'disputa' mais geral acerca do poder de definição dos fenômenos econômicos. Nesse sentido, uma agenda de pesquisa efetivamente socioantropológica acerca do desenvolvimento e seus processos parte da rejeição a determinismos economicistas, permitindo reequacionar o desenvolvimento econômico à própria mudança, visto que ela se identifica com totalidades sociais efetivas. A economia, compreendida como uma fração dessas totalidades, é incapaz de determiná-las.

Abordagens centradas em agentes privilegiados, em especial econômicos, como CTNs, tendem a reforçar diversas modalidades de reducionismo, assim como a estimular con- cepções normativas acerca de seu papel nos fenômenos relacionados ao desenvolvimento. Nesse sentido, o artigo defende uma abordagem relacional multiagente do desenvolvimento econômico, tendo ilustrado sua eficácia na compreensão da implantação de grandes projetos e seus efeitos sobre a dinâmica econômica e sociopolítica da Amazônia Oriental a partir dos anos 1980.

O caso em questão permitiu, ainda, observar a inadequação de abordagens uniescalares e concepções centradas no local para o entendimento de fenômenos contemporâneos. Em particular, as múltiplas formas de agência econômica e não econômica presentes no PFC e no PFC S11D apontaram o entrecruzamento de escalas local, nacional, mesorregional e transnacional como fator crítico na conformação do processo de desenvolvimento da Amazônia Oriental. De modo geral, determinações translocais na implantação dos projetos e estratégias locais e translocais executadas por agentes sociais favorecem amplamente o argumento em favor de uma concepção multiescalar e em rede dos processos de desenvolvimento.

Em paralelo, a defesa de uma compreensão centrada nas expressões extremas do desenvolvimento, i. e. GPIs e PGEs, permitiu articular as dimensões estrutural e da ação em processos de desenvolvimento efetivos. Nesse sentido, o desenvolvimento econômico é determinado pela evidência da mudança social, seu conteúdo substantivo, constituindo um subtipo específico que remete a uma transformação profunda da natureza dos agentes, de suas relações e das estruturas sociais. Constitui, portanto, um processo de recomposição abrangente das relações entre os agentes econômicos, políticos e sociais, acelerando e transformando qualitativamente a estrutura social a partir de conflitos em situações ou contextos efetivos. No que respeita à sua forma, o que está em jogo é o processo concreto de transformação estrutural, as alianças e conflitos que emergem à medida que uma dada estrutura social é impactada por fenômenos indutores da mudança social. 
Finalmente, a agenda em torno do desenvolvimento assume, como seu principal desafio, o enfrentamento da normatividade frequentemente adstrita à transição social. Sua compreensão como transformação estrutural, envolvendo riscos efetivos ou potenciais à reprodução social, assim como impacto diferencial sobre agentes e grupos sociais, implica que o desenvolvimento econômico é um fenômeno moralizável ${ }^{21}$ por excelência. Nesse sentido, o desenvolvimento é apreendido como mudança positiva ou negativa - até mesmo neutra quanto às posições relacional e estrutural do agente. Contingentes populacionais urbanos, trabalhadores rurais, comunidades tradicionais, crianças e mulheres, trabalhadores na mineração e na siderurgia a carvão vegetal, todos afetados de modo assimétrico pela duplicação da EFC em suas condições de reprodução, tendem a experimentar o desenvolvimento a partir de parâmetros normativos profundamente diversos. Tais parâmetros diferem ainda mais radicalmente dos modos através dos quais investidores públicos (e. g. BNDES) e privados (e. g. acionistas na bolsa de Nova Iorque) são impactados - e concebem esse impacto - quanto a seus recursos estratégicos e condições de reprodução.

Dessa forma, de uma perspectiva socioantropológica, o desenvolvimento econômico é um fenômeno eminentemente amoral, no sentido de que sua demonstração independe da evidência de resultados - positivos ou negativos - relacionados a desempenho econômico e (ou) político-institucional. Consequentemente, o desenvolvimento não é 'bom' ou 'mau', nem possui aspectos positivos ou negativos; antes, é vivido de forma diferenciada, a partir de categorias morais. Assim, a mudança social é decididamente experimentada como redefinição das condições de reprodução social de agentes e grupos sociais, podendo ser vivenciada inclusive, como tragédia.

Em outras palavras, o desenvolvimento

${ }^{21}$ Assim como um fenômeno moralizante, visto que imputa qualidades ou propriedades morais aos agentes nele implicados. econômico é uma forma moralizável, embora amoral, de mudança social. De uma perspectiva moral - na qual incorre parcela substancial das elaborações macrossociológicas discutidas, mas também interpretações teóricas influentes no subcampo da antropologia do desenvolvimento (Escobar, 1995) -, a mudança é positiva ou negativamente construída mediante 'métricas' morais específicas. Entretanto, a mudança social em geral, assim como os processos contemporâneos de desenvolvimento econômico, tais como aqueles concretamente induzidos pelo PFC e pelo PFC S11D na Amazônia Oriental, derivam das relações de poder e conflitos sociais efetivos, que determinam o caráter e o curso da transição pela qual passam os agentes e os grupos envolvidos. E essa existência concreta é única e diferenciada; parte dela é impactada por 'benefícios', e outra, por 'malefícios', de modo que o desenvolvimento econômico representa, simultaneamente, ambas as condições.

Recebido para publicação em 21 de janeiro de 2016 Aceito em 23 de abril de 2016

\section{REFERÊNCIAS}

ALMEIDA, D. Domingos. Infográfico apresenta dados sobre aumento de manifestações no corredor de Carajás. Açailândia: Justiça nos Trilhos, 2015.

ASSIS, William Santos de; CARNEIRO, Marcelo. D. Sampaio. Uso del carbón vegetal como fuente de energía para el parque siderúrgico de Carajás: controversias ambientales, sociales y económicas. In: TONI, F; PORRO, R. (Eds.). Energía, medio ambiente y desarrollo en la Amazonía. Madrid: Editorial Academica Espanola, 2012. p. 242-267.

BARÉ, J. F. A antropologia e as políticas de desenvolvimento: algumas orientações. Terrain, S.l., n. 17, 2004.

BELTRÃO, P. C. Sociologia do Desenvolvimento. Porto Alegre: Globo, 1965.

BIERSCHENK, T. et al. Local development brokers in Africa: the rise of a new social category. IFAS Working Papers, S.l., n. 13, p. 1-44, 2002.

BNDES. BNDES aprova financiamento de R\$ 7,3 bilhões para vale realizar investimentos no Brasil até 2012. 2008.

BORGES, A.; GÓES, F. Ibama autoriza maior projeto de mineração da história da vale. Rio de Janeiro:_Valor Econômico, 2013.

BOSSI, D. et al. A Face Agressiva da Vale. In: INSTITUTO ROSA LUXEMBURG STIFTUNG (Ed.). Empresas transnacionais brasileiras na América Latina: um debate necessário. São Paulo: Espressão Popular, 2009. p. 159-174. 
BRANDÃO LOPES, J. R. Sociedade industrial no Brasil. Difusão Européia do Livro, 1964.

. Desenvolvimento e mudança social: formação da sociedade urbano-industrial no Brasil. $3^{\mathrm{a}}$ ed. São Paulo/ Brasília: Editora Nacional/INL, 1976. 240p.

BUNKER, S. G.; CICCANTELL, P. S. Globalization and the race for resources. S.l: The Johns Hopkins University Press, 2005.

BURAWOY, M. Introduction: reaching for the global. In: BURAWOY, M. (Ed.). Global ethnography: forces, connections, and imaginations in a postmodern world. Berkeley: University of California Press, 2000. p. 1-40.

CARDOSO DE MELLO, J. M. Capitalismo tardio. São Paulo: Brasiliense, 1982. 183p.

CARDOSO, F. H. Sociologie du développment en Amérique Latine. Paris: Anthropos, 1969. 264p.

CARDOSO, F. H.; FALETTO, E. Dependência e desenvolvimento na América Latina: ensaio de interpretação sociológica. São Paulo: Zahar, 1967.

CARNEIRO, M. D. S. O programa grande Carajás e a dinâmica política na área de influência da ferrovia: políticas públicas e poder local na Amazônia. In: CASTRO, E. M. R. D.; MOURA, E. A. F. et al. (Eds.). Industrialização e grandes projetos: desorganização e reorganização do espaço. Belém: EdUFPA, 1994. p. 187-219.

Do latifúndio agropecuário à empresa latifundiária carvoeira: a EFCarajás e a propriedade da terra no Oeste Maranhense. In: COELHO, M. C. N.; COTA, R. G. (Eds.). Dez anos da estrada de ferro Carajás. Belém: EdUFPA/ NAEA, 1997. p. 223-250.

Práticas, discursos e arenas: notas sobre a socioantropologia do desenvolvimento. Sociologia \& Antropologia, Rio de Janeiro, v. 2, n. 4, p. 129-158, 2012.

CARVALHO, P. S. L. D. et al. Minério de ferro. BNDES Setorial, Rio de Janeiro, n. 39, p. 197-234, 2014.

CESARINO, L. Antropologia multissituada e a questão da escala: reflexões com base no estudo da cooperação sul-sul brasileira. Horizontes Antropológicos, Porto Alegre, v. 20, n. 41 , p. 19-50, 2014.

COELHO, T. P. Projeto grande carajás: trinta anos de desenvolvimento frustrado. Marabá: Iguana Editorial, 2015. 160p.

COSTA PINTO, L. D. A. Resistências à mudança: fatores que impedem ou dificultam o desenvolvimento. Centro $\therefore$ Latino-Americano de Pesquisa em Ciências Sociais, Rio de

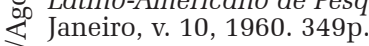

N COSTA PINTO, L. D. A.; BAZZANELLA, W. (Eds.). Teoria i. do desenvolvimento. Rio de Janeiro: Zahared. 1967.

N

di de Janeiro: Zahar, 1969.

Sociologia e desenvolvimento. $4^{\mathrm{a}} \mathrm{ed}$. Rio de Janeiro: Civilização Brasileira, 1972.

iे DE SARDAN, J. P. O. Anthropologie et développement: essai $>$ en socio-anthropologie du changement social. Karthala, if 1995. 224p.

. Anthropology and development: understanding contemporary social chage. London/New York: Zed Books, 2005. 256p. DIAS, F. C. Presença de Max Weber na sociologia brasileira contemporânea. Revista de Administração de Empresas, São Paulo, v. 14, n. 4, p. 47-62, jul./ago.1974.

DICKEN, P. Global shift: mapping the changing contours of 3 the world economy. New York: The Guilford Press, 2011.
DURÃO, V. S.; GÓES, F. Vale planeja investir R\$ 40 bi em Serra Sul. Rio de Janeiro: Valor Econômico, 2012.

DURÃO, V. S.; ROSAS, R. BNDES aprova R\$ 3,9 bi para projeto da vale no MA. Rio de Janeiro: Valor Econômico, 2012.

ELIAS, N. Conceitos Sociológicos Fundamentais. In: NEIBURG, F.; WAIZBORT, L. (Eds.). Escritos \& ensaios: estado, processo, opinião pública. Rio de Janeiro: Jorge Zahar, 2006. v.1. p. 21-33.

ELWERT, G.; BIERSCHENK, T. Development aid as an intervention in dynamic systems: an introduction. Sociologia ruralis, Estados Unidos, v. 28, n. 2-3, p. 99-112, 1988.

ESCOBAR, A. Anthropology and the development encounter: the making and marketing of development anthropology. American Ethnologist, Barcelona, v. 18, n. 4, p. 658-682, 1991.

Encountering development: the making and unmaking of the third world. Princeton. New Jersey: Princeton University Press, 1995. 291p.

Anthropology and Development. International Social Science Journal, Estados Unidos, v. 49, n. 154, p. 497-515, 1997.

EVANS, P. B. Autonomia e parceria: estados e transformação industrial. Rio de Janeiro: Editora UFRJ, 2004. 404p.

FAUSTINO, C.; FURTADO, F. Mineração e violação de direitos: o projeto ferro Carajás S11D da Vale. Relatório da missão de investigação e incidência. Açailância: DHESCA Brasil, 2013.

FERGUSON, J. The anti-politics machine: 'development', depoliticization and bureaucratic power in Lesotho. Estados Unidos: University of Minnesota Press, 1990. 336p.

Expectations of modernity: myths and meanings of urban life on the Zambian Copperbelt. Califórnia: University of California Press, 1999.

FERREIRA, G. E. et al. A indústria brasileira de gusa de mercado. Rio de Janeiro: CETEM/MCT, 2006. 67 p.

FRATTOLILLO, O. Beyond Japan's foreign 'aid fatigue': the path from the cold war gaiatsu to the new millennium agenda. Asia-Pacific Journal of Social Science, India, n. 3 p. 16-32, 2012.

GERMANI, G. Sociologia da modernização: estudos teóricos, metodológicos e aplicados a América Latina: Mestre Jou, 1974.

GÓES, F. BNDES aprova R\$ 6,2 bi para projeto da vale em Carajás. Rio de Janeiro: Valor Econômico, 2014.

GOMES, R. A.; FAURE, X.; MENESES, V. Jean Pierre Olivier De Sardan e a socioantropologia do desenvolvimento. Raízes, Campina Grande, v. 32, n. 2, p. 5-8, 2015.

HENDERSON, J. et al. Redes de produção globais e a análise do desenvolvimento econômico. Revista Pós Ciências Sociais, Maranhão, v. 9, n. 15, p. 143-140, 2011.

HILDEBRAND, W. R.; SAMPAIO, J. A. Província mineral de Carajás. In: SAMPAIO, J. A et al. (Eds.). Usinas de Beneficiamento de Minérios do Brasil. Rio de Janeiro: CETEM/MCT, 2001. p. 77-83.

IVO, A. B. L. O paradigma do desenvolvimento: do mito fundador ao novo desenvolvimento. Caderno $\mathrm{CRH}$, Salvador, v. 25, n. 65, p. 187-210, 2012.

KNOWLES, C. Trajetórias de um chinelo: microcenas da globalização. Contemporânea, v. 4, n. 2, p. 289-310, 2014.

LEAHY, J. Vale warned by Fitch on rating after dam disaster. London: Financial Times, 2015.

LEME, A. A.; BRASIL JR., A. D. S. Sociologia do 
desenvolvimento e pensamento social no Brasil: proposta para uma agenda de pesquisa. Revista Crítica e Sociedade, Minas Gerais, v. 4, n. 2, p. 6-34, 2015.

MACHADO NETO, A. L. Sociologia do desenvolvimento: ensaios. Rio de Janeiro: Tempo Brasileiro, 1963

MARCUS, G. E. Ethnography in/of the world system: the emergence of multi-sited ethnography. Annual Review of Anthropology, Houston, v. 24, p. 95-117, 1995.

MCGRATH-CHAMP, S. et al. Global destruction networks, the labour process and employment relations. Journal of Industrial Relations, Austrália, v. 57, n. 4, p. 624-640, 2015.

MINÉRIOS \& MINERALES. Carajás deu início à globalização da vale. São Paulo: Minérios \& Minerales, 2011.

MONTEIRO, M. D. A. Siderurgia na Amazônia Oriental Brasileira e a pressão sobre a floresta primária.In: II ENCONTRO DA ANPPAS. Indaiatuba: ANPPAS, 2004.

MONTEIRO, M. D. A. et al. Impactos ambientais da estrada de ferro Carajás no Sudeste do Pará. In: TEIXEIRA, J. B. G.; BEISIEGEL, V. D. R. (Eds.). Carajás: geologia e ocupação humana. Belém: Museu Paraense Emílio Goeldi, 2006. p. 470.

NIEPONICE, G. et al. Value creation in mining 2015: beyond basic productivity. The. Boston: BCG Boston Consulting Group, 2015, 28 p.

OLIVEIRA, A. L. R. D. Projeto Carajás, práticas indigenistas e os povos indígenas no Maranhão. Revista Anthropológicas, Recife, v. 15, n. 2, p. 135-170, 2011.

PEREIRA, L. Urbanização e subdesenvolvimento. Rio de Janeiro: Zahar Editores, 1969.

Ensaios de sociologia do desenvolvimento. São Paulo: Livraria Pioneira Editôra, 1970. 158p.

Subdesenvolvimento e desenvolvimento. $2^{\mathrm{a}}$ ed. Rio de Janeiro: Zahar, 1973. p.218, (Textos Básicos de Ciências Sociais)

PHILLIPS, N. et al. The social foundations of global production networks: towards a global political economy of child labour. Third World Quarterly, Londres, v. 35, n. 3, p. 428-446, 2014.

PHILLIPS, N.; SAKAMOTO, L. Global production networks, chronic poverty and 'slave labour'in Brazil. Studies in Comparative International Development, Estados Unidos, v. 47, n. 3, p. 287-315, 2012.

PINTO FERREIRA, L. Sociologia do Desenvolvimento. $3^{\mathrm{a}}$.ed. Rio de Janeiro: Editora Rio, 1978. 159p.

PIQUET, R. Cidade-empresa: presença na paisagem urbana brasileira. Rio de Janeiro: Jorge Zahar, 1998.

POEMAS. Antes fosse mais leve a carga: avaliação dos aspectos econômicos, políticos e sociais do desastre da Samarco/Vale/BHP em Mariana (MG). Rio de Janeiro, 2015. $100 \mathrm{p}$

POLANYI, K. A Grande transformação: as origens de nossa época. $2^{\mathrm{a}}$ ed. Rio de Janeiro: Campus, 2000.

PRATES, D. M. A alta recente dos preços das commodities. Revista de Economia Política, São Paulo, v. 27, n. 3, p. 323$344,2007$.

RADOMSKY, G. F. W. Desenvolvimento, pós-estruturalismo e pós-desenvolvimento. A crítica da modernidade e a emergência de "modernidades" alternativas. Revista Brasileira de Ciências Sociais, São Paulo, v. 26, n. 75, p. 149-193, 2011.

RAMALHO, J. R.; OLIVEIRA, R. V. D. A atualidade do debate sobre trabalho e desenvolvimento. Caderno $C R H$, Salvador, v. 26, n. 68, p. 211-215, 2013

RAMALHO, J. R. G. P.; FORTES, A. Desenvolvimento, trabalho e cidadania: baixada e Sul Fluminense. Rio de Janeiro: Sete Letras, 2012.

RIBEIRO, B. Vale diz que investimento em minério em Serra Sul depende da demanda. Rio de Janeiro: Valor Econômico, 2004.

RIBEIRO, G. L. ¿Cuánto más grande mejor? Proyectos de gran escala: una forma de producción vinculada a la expansión de sistemas económicos. Desarrollo Económico, Buenos Aires, v. 27, n. 105, p. 3-27, 1987.

Poder, redes e ideologia no campo do desenvolvimento. Novos Estudos CEBRAP, | São Paulo, n. 80 , p. $109-125,2008$

ROYLE, R. Titãs do minério de ferro tiram pequenos concorrentes do mercado. New York: The Wall Street Journal, 2015.

SANTOS, R. S. P. A forja de vulcano: siderurgia e desenvolvimento na Amazônia Oriental e no Rio de Janeiro. 2010. 275 p. Tese (Doutorado) - Programa de Pósgraduação em Sociologia e Antropologia, Universidade Federal do Rio de Janeiro.

; MILANEZ, B. The Global Production Network for iron ore: materiality, corporate strategies, and social contestation in Brazil. The Extractive Industries and Society, Canadá, v. 2, n. 4, p. 756-765, $2015 a$.

Redes globais de produção (RGPS) e conflito socioambiental: a Vale S.Á. e o complexo minerário de Itabira. IN: VII SIMPÓSIO INTERNACIONAL DE GEOGRAFIA AGRÁRIA. Goiânia: SINGA, 2015b. p.20932108

SARAIVA, A. BNDES aprova financiamento de $R \$ 6,2$ bilhões para expansão da Vale. Rio de Janeiro: Valor Econômico, 2014.

SCHRÖDER, P. A Antropologia do Desenvolvimento: é possível falar de uma subdisciplina verdadeira? Revista de Antropologia, São Paulo, v. 40, n. 2, p. 83-100, 1997.

Os desafios para uma antropologia do desenvolvimento no cenário atual. IN:29 REUNIÃO DA ABA. Natal: ABA, 2014. p.1-20.

SZTOMPKA, P. A Sociologia da mudança social. $2^{\mathrm{a}}$ ed. Rio de Janeiro: Civilização Brasileira, 2005. 576p.

TREECE, D. Bound in misery and iron: the impact of the grande Carajás programme on the indians of Brazil. London: Survival International (with Friends of the Earth), 1987. $151 \mathrm{p}$

TRINER, G. D. Mining and the state in Brazilian development. London: Pickering \& Chatto, 2011.

VAINER, C. B. Grandes projetos e organizacão territorial: os avatares do planejamento regional. In: MARGULIS, S. (Eds.). Meio ambiente: aspectos técnicos e econômicos. Brasília: IPEA, 1990. p. 238.

VALE. Vale: nossa história. Rio de Janeiro: Verso Brasil, 2012. $420 \mathrm{p}$

Projeto ferro Carajás S11D: um novo impulso ao desenvolvimento sustentável do Brasil. Rio de Janeiro, 2013. $47 \mathrm{p}$.

. Relatório anual 2015. 2016. 181 p.

WILSON, J. D. Chinese resource security policies and the restructuring of the Asia-Pacific iron ore market. Resources Policy, Cambridge, v. 37, n. 3, p. 331-339, 2012.

Governing Global Production: resource networks in the Asia-Pacific steel industry. Basingstoke: PalgraveMacmillan, 2013. 


\section{ECONOMIC DEVELOPMENT AND SOCIAL CHANGE: "Vale" and mining in Oriental Amazon}

\author{
Rodrigo Salles Pereira dos Santos
}

This article proposes an anthropological theoretical contribution about the phenomenon of economic development and its contemporary expressions, integrating them to the tradition of social change. It brings the sociological debate about Brazilian development and dialogues with Development Anthropology subfield, focusing Oriental Amazon as an empirical frame that defies single scaled conceptions centered in privileged agents. Implantation of mineral extraction of iron in 1980's and its exponential expansion in the 2000's through "great projects" such as the PFC and the PFC S11D demonstrate the inductive capacity of structural transformation, but evidence, parallelly, its social nature, complex and multi-scaled. Thus, this article emphasizes the relations between agency, interaction and social structure, locating the progressive relevance of organization patterns of contestation in multi-agent networks with a transnational scope. The investigation relies on bibliographical research and literature reviews, as well as, secondarily, field research and direct observation.

KEYwords: Economic development. Social change. Great projects. Mining. Vale.

\author{
DÉVELOPPEMENT ÉCONOMIQUE ET \\ CHANGEMENT SOCIAL: la "Vale" et \\ l'exploitation minière dans l'Est de l' Amazonie \\ Rodrigo Salles Pereira dos Santos
}

Cet articlese veut de donner une contribution socio-anthropologique théorique au phénomène de développement économique et à ses expressions contemporaines en les intégrant dans la tradition du changement social. On y récupère le débat concernant la sociologie du développement brésilien et on y dialogue avec le sous-domaine de l'anthropologie du développement, en mettant l'accent sur l'Est de l'Amazonie comme découpage empirique qui met au défi les conceptions d'échelles unidimensionnelles centrées sur des agents privilégiés. L'implantation de l'extraction minérale de fer dans les années 1980 et son expansion exponentielle à partir des années 2000, via les "grands projets" - le PFC et le PFC S11D - ont démontré la capacité d'induction de transformation structurelle mais ont aussi, en parallèle, mis en évidence sa nature sociale, complexe et à échelle multidimensionnelle. C'est ainsi que l'article met l'accent sur les relations entre agence, interaction et structures sociales. Il permet de situer l'importance progressive des modes d'organisation pour la contestation dans les réseaux multiagents de portée transnationale. L'investigation est basée sur une recherche bibliographique et une révison des publications et, en deuxième lieu, sur un travail sur le terrain et à partir d'observations directes.

Mots-CLÉs:Développement économique. Changement social. Grands projets. Minération. Vale. Dpto. de Sociologia e do Programa de Pós-Graduação em Sociologia \& Antropologia (PPGSA), Universidade Federal do Rio de Janeiro (UFRJ). Atua em Sociologia Econômica, do Desenvolvimento e do Trabalho. Possui experiência nos temas: mudança social, globalização, desenvolvimento, estratégia corporativa, mineração, siderurgia e indústria automobilística. Coordena o grupo de pesquisa Política, Economia, Mineração, Ambiente e Sociedade (PoEMAS), é membro do Comitê Nacional em Defesa dos Territórios frente à Mineração (CNDTM) e assessora o Movimento Nacional pela Soberania Popular frente à Mineração (MAM). Publicações recentes: Huw Beynon: marxismo e sociologia (Entrevista). Sociologia \& Antropologia, v. 6, p. 13-29, 2016; Da estratégia corporativa à ação economicamente relevante: a CSN e a contestação social na mineração de ferro. Revista Pós Ciências Sociais, v. 12, p. 143-166, 2015; Topsy-Turvy NeoDevelopmentalism: an analysis of the current Brazilian model of development, v. 53, p. 12-28, 2015 